\title{
Improvement in mechanical properties in AIN-h-BN composites with high thermal conductivity
}

\author{
Zetan LIU, Shiqiang ZHAO, Tian YANG, Ji ZHOU* \\ State Key Laboratory of New Ceramics \& Fine Processing, School of Materials Science \\ and Engineering, Tsinghua University, Beijing 100084, China
}

Received: February 20, 2021; Revised: May 12, 2021; Accepted: June 3, 2021

(C) The Author(s) 2021.

\begin{abstract}
It is possible to improve the machinability of aluminum nitride-hexagonal boron nitride (AlN-h-BN) ceramics while maintaining high strength and high thermal conductivity. The composite ceramics with $0-30 \mathrm{wt} \% \mathrm{BN}$ as secondary phase were prepared by hot pressed sintering, using yttrium oxide $\left(\mathrm{Y}_{2} \mathrm{O}_{3}\right)$ as sintering aid. The phase composition, density, microstructure, mechanical properties, thermal conductivity, and dielectric properties were investigated. The sintering additives were favorable to purify the grain boundaries and improve densification, reacting with oxide impurities on the surface of raw material powder particles. The optimum BN content improved the flexural strength and fracture toughness of composite ceramics with $475 \mathrm{MPa}$ and $4.86 \mathrm{MPa} \cdot \mathrm{m}^{1 / 2}$, respectively. With increasing the amount of $\mathrm{BN}$, the thermal conductivity and hardness of composites gradually decreased, but the minimum value of thermal conductivity was still $85.6 \mathrm{~W} \cdot \mathrm{m}^{-1} \cdot \mathrm{K}^{-1}$. The relative dielectric constant and dielectric loss tangent of the samples ranged from 6.8 to 8.3 and from $2.4 \times 10^{-3}$ to $6.4 \times 10^{-3}$, respectively, in $22-26 \mathrm{GHz}$.
\end{abstract}

Keywords: aluminum nitride (AIN); boron nitride (BN); mechanical properties; thermal conductivity

\section{Introduction}

In recent years, the development of large-scale integrated circuits, semiconductor module circuits, high-power devices, and 5G technology has placed higher requirement on heat dissipation and packaging ceramic materials. So far alumina ceramics are the most used substrate materials in the electronics industry, with good mechanical strength (450-550 MPa) and chemical stability [1]. However, the relatively low thermal conductivity $\left(36-39 \mathrm{~W} \cdot \mathrm{m}^{-1} \cdot \mathrm{K}^{-1}\right)$ of alumina limits its application at higher standards [2]. Beryllium oxide

\footnotetext{
* Corresponding author.

E-mail: zhouji@tsinghua.edu.cn
}

ceramics with high thermal conductivity $\left(250 \mathrm{~W} \cdot \mathrm{m}^{-1} \cdot \mathrm{K}^{-1}\right)$ and good shock resistance, also occupy a priority status in the heat dissipation substrate. Although high purity beryllium oxide ceramics are very safe, the powders of beryllium oxide are highly toxic, which hampers their further development $[3,4]$. It is of great significance to develop the ceramic substrate material with excellent comprehensive performance.

Aluminum nitride (AIN) ceramic has some excellent properties, such as good insulation, high thermal conductivity, low density, high strength, high temperature resistance, melt metal corrosion resistance, and low dielectric constant [5-7], considering to be an ideal material for new generation of highly integrated semiconductor substrates and electronic device 
packaging, and other places that require heat conduction and strength support $[8,9]$. However, due to the high hardness of aluminum nitride and its relatively low fracture toughness (around $3 \mathrm{MPa} \cdot \mathrm{m}^{1 / 2}$ ) [10], the cost and difficulty of processing increase because of its brittle fracture behavior. Considering the manufacture of precision parts to utilize AlN, it is important to improve the machinability of materials and maintain relative excellent comprehensive performance. Therefore, it is a good choice to fabricate multiphase ceramics by means of composite design to improve machinability. Hexagonal boron nitride (h-BN) also known as white graphite is laminate structure ceramic materials, having the characteristics of low hardness, good electrical insulation, low dielectric constant, high temperature stability, good thermal conductivity, good chemical inertness, and so on. Moreover, a series of studies have been carried out to improve machinability using h-BN, such as $\mathrm{SiC}-\mathrm{h}-\mathrm{BN}, \mathrm{SiO}_{2}-\mathrm{h}-\mathrm{BN}, \mathrm{Al}_{2} \mathrm{O}_{3}-\mathrm{h}-\mathrm{BN}, \mathrm{Si}_{3} \mathrm{~N}_{4}-\mathrm{h}-$ $\mathrm{BN}$, and zirconia-toughened alumina (ZTA)-h-BN [11-16]. Based on this, there is a good expectation to prepare AlN-h-BN composite ceramics. Since both AlN and h-BN are the covalent compound, it is difficult to achieve near complete densification by conventional pressureless sintering method subjecting to limited atomic mobility in the sintering process [17]. The hot pressing method can provide a way to not only shorten sintering time, but also effectively improve the sintering densification [18]. Jin et al. [19] prepared capsule-like h-BN-coated AlN powders by nitridation reaction in nitrogen gas, and sintered by hot-pressing with various BN content. The flexural strength of the composite ceramics decreased slowly when the BN content was increased. Makarenko et al. [20] utilized low-temperature aluminum diboride $\left(\mathrm{AlB}_{2}\right)$ as a precursor to produce the composite AlN-BN-based powders. Then the compact samples were hot pressed from the synthesized powders with the bending strength of 235-240 MPa. He et al. [21] prepared AlN-BN composites using $\mathrm{Sm}_{2} \mathrm{O}_{3}-\mathrm{CaF}_{2}$ as sintering additives by spark plasma sintering. They researched the additives and $\mathrm{h}-\mathrm{BN}$ content on the properties of samples, showing that the highest thermal conductivity value was $85 \mathrm{~W} \cdot \mathrm{m}^{-1} \cdot \mathrm{K}^{-1}$ when introducing $8 \mathrm{wt} \%$ sintering aids. Jin et al. [22] studied the influence of $\mathrm{BN}$ content on the properties of AlN-BN ceramics without sintering additives by hot pressing. The results suggest that the bending strength and fracture toughness decreased apparently as the content of boron nitride increased. The thermal conductivity of single-phase AlN was only $81.2 \mathrm{~W} \cdot \mathrm{m}^{-1} \cdot \mathrm{K}^{-1}$, and even lower for multiphase ceramics. Therefore, how to improve the comprehensive performance of AlN-BN composites still needs to be further studied. In this paper, we prepared AlN-h-BN composites with the sintering additive of $\mathrm{Y}_{2} \mathrm{O}_{3}$ by hot pressing from commercial AlN and h-BN powders. The effect of h-BN content on the densification, phase constitution, microstructure, mechanical properties, and dielectric properties of the sintered specimens was assessed. The purpose of this work is to improve the machinability of composites and at the same time make the AlN-BN ceramics have the relatively high thermal conductivity and good mechanical properties.

\section{Experimental}

Commercially available powders used in this study were AlN (grade E, $d_{50}=1.09 \mu \mathrm{m}$; Tokuyama Co., Yamaguchi, Japan), h-BN (99.9\% purity, 1-2 $\mu \mathrm{m}$; Shanghai Aladdin Bio-Chem Technology Co., Ltd., China), and $\mathrm{Y}_{2} \mathrm{O}_{3}(99.9 \%$ purity; Shanghai Aladdin Bio-Chem Technology Co., Ltd., China). The oxygen content in the AlN and h-BN starting powders was 0.77 and $0.50 \mathrm{wt} \%$, respectively, according to oxygen/nitrogen analyzer (ON-3000, NCS Testing Technology Co., Ltd., China). $\mathrm{Y}_{2} \mathrm{O}_{3}$ was utilized as sintering additive. The compositions of samples are shown in Table 1.

Firstly, scaled raw powders were ball mixed for $12 \mathrm{~h}$ using high-purity zirconia milling balls. Anhydrous ethanol is used as ball mill medium. Then the slurries were addressed at $65{ }^{\circ} \mathrm{C}$ in a rotary vacuum evaporator. The powder mixture was additionally dried for $24 \mathrm{~h}$ at $80{ }^{\circ} \mathrm{C}$ in drying oven and screened through a 200-mesh sieve to minimize powder agglomeration. Finally, the powder mixtures were sintered in the hot press furnace (heating rate: $20{ }^{\circ} \mathrm{C} / \mathrm{min}$; HP P $12.54 \mathrm{LA}, \mathrm{FCT}$ Systeme GmbH, Germany) at $1900{ }^{\circ} \mathrm{C}$ for $1 \mathrm{~h}$ under a pressure of $50 \mathrm{MPa}$ in nitrogen atmosphere. The size of

\begin{tabular}{|c|c|c|c|}
\hline \multirow{2}{*}{ Sample } & \multicolumn{2}{|c|}{ Formulation (wt $\%)$} & \multirow{2}{*}{$\frac{\text { Sintering aid }(w t \%)}{\mathrm{Y}_{2} \mathrm{O}_{3}}$} \\
\hline & AlN & $\mathrm{BN}$ & \\
\hline $\mathrm{A} 100 \mathrm{Y}$ & 100 & 0 & 5 \\
\hline A95BY & 95 & 5 & 5 \\
\hline A90BY & 90 & 10 & 5 \\
\hline A80BY & 80 & 20 & 5 \\
\hline A70BY & 70 & 30 & 5 \\
\hline
\end{tabular}


obtained compacts was $50 \mathrm{~mm}$ in diameter and $6 \mathrm{~mm}$ in thickness. The graphite gasket layer of disks was removed by diamond grinding wheel.

The bulk density of specimens was measured by Archimedes method using water as immersing medium, and the theoretical density was calculated by the rule of mixture. The phase composition was determined by $\mathrm{X}$-ray diffraction analysis (XRD; D/max-2550, Rigaku, Japan) using $\mathrm{Cu} \mathrm{K} \alpha$ radiation. The fracture morphology of the sintered composites was examined by field emission scanning electron microscope (SEM; Merlin, Zeiss, Germany). The transmission electron microscope (TEM; JEM-2100F, JEOL Ltd., Japan) with high resolution transmission electron microscope (HRTEM) mode was used to characterize the microstructure of the samples. The flexural strength at room temperature was investigated by three-point bending tests (AG-IC, SHIMADZU, Japan) with a span width of $30 \mathrm{~mm}$ and a crosshead speed rate of $0.5 \mathrm{~mm} / \mathrm{min}$ on chamfered rectangular (size: $3 \mathrm{~mm} \times 4 \mathrm{~mm} \times 36 \mathrm{~mm}$ ) bar. The stressed surface of the test sample was polished. The fracture toughness was measured by single edge notched beam method (AG-IC, SHIMADZU, Japan) with a $16 \mathrm{~mm}$ span and a loading rate of $0.05 \mathrm{~mm} / \mathrm{min}$ using $2 \mathrm{~mm} \times 4 \mathrm{~mm} \times 22 \mathrm{~mm}$ test bar. The hardness was determined by Vickers indentation (Tukon 2500, Wilson, USA) using a load of $5 \mathrm{~kg}$ and a holding time of $10 \mathrm{~s}$ on polished surface. These mechanical property tests were performed on the surface perpendicular to the $z$-axial direction that paralleling to the pressing direction of sintering, and seven specimens were used for each item.

The laser flash method (LFA 467 HT, Netzsch, Germany) was used to measure the thermal diffusivity $(\alpha)$ and specific heat capacity $\left(C_{\mathrm{p}}\right)$ of specimens (size: $10 \mathrm{~mm} \times 10 \mathrm{~mm} \times 2.5 \mathrm{~mm}$ for $z$-axial direction) at room temperature according to ASTM E-1461-2013. Thermal conductivity of the composites was calculated by the equation:

$$
\lambda=\alpha \rho C_{\mathrm{p}}
$$

where $\lambda$ is the thermal conductivity and $\rho$ is the density. Data was averaged on three measurements for each sample.

Dielectric constant and dielectric loss $(\tan \delta)$ were measured on the vector network analyzer (N5230C, Heysight, USA) within the range of $22-26 \mathrm{GHz}$ at room temperature, deriving with scattering parameter by waveguide transmission/reflection method [23]. The size of specimens is $8.62 \mathrm{~mm} \times 4.30 \mathrm{~mm} \times 3.67 \mathrm{~mm}$.

\section{Results and discussion}

\section{1 Phase composition}

The XRD patterns of sintered ceramics containing various contents of $\mathrm{BN}$ are shown in Fig. 1. For all composites, the phases of $\mathrm{AlN}$ and $\mathrm{BN}$ in the raw materials are clearly identified but $\mathrm{Y}_{2} \mathrm{O}_{3}$ phase. There is no phase of zirconia contamination introduced by the powder mixing process. In addition, the new phases of $\mathrm{YAlO}_{3}$ (YAP) and $\mathrm{Y}_{4} \mathrm{Al}_{2} \mathrm{O}_{9}$ (YAM) were found out in the patterns. This is because $\mathrm{Y}_{2} \mathrm{O}_{3}$ reacted with oxidizing impurities in the raw powders to form the new phases at high temperature in which $\mathrm{Al}_{2} \mathrm{O}_{3}$ originated from the spontaneously oxidation of raw AlN powder. According to the calculation of oxygen content in the raw materials, the minimum molar ratio for $\mathrm{Y}_{2} \mathrm{O}_{3}$ and $\mathrm{Al}_{2} \mathrm{O}_{3}$ was 1.31: 1 in sample of A100Y. During the sintering process, $\mathrm{Y}_{2} \mathrm{O}_{3}$ was consumed by Reactions (2) and (3). Similar phenomena have been reported in the AlN ceramics sintering process [24-26]. With the increase of the h-BN content, the diffraction peaks of h-BN gradually become stronger. In addition, the intensity contrast of different $(h k l)$ peaks of YAP, such as (101) and (002) peaks, differs in different samples, showing the different orientation of YAP.

$$
\begin{gathered}
\mathrm{Y}_{2} \mathrm{O}_{3}+\mathrm{Al}_{2} \mathrm{O}_{3} \rightarrow 2 \mathrm{YAlO}_{3} \\
2 \mathrm{Y}_{2} \mathrm{O}_{3}+\mathrm{Al}_{2} \mathrm{O}_{3} \rightarrow \mathrm{Y}_{4} \mathrm{Al}_{2} \mathrm{O}_{9}
\end{gathered}
$$

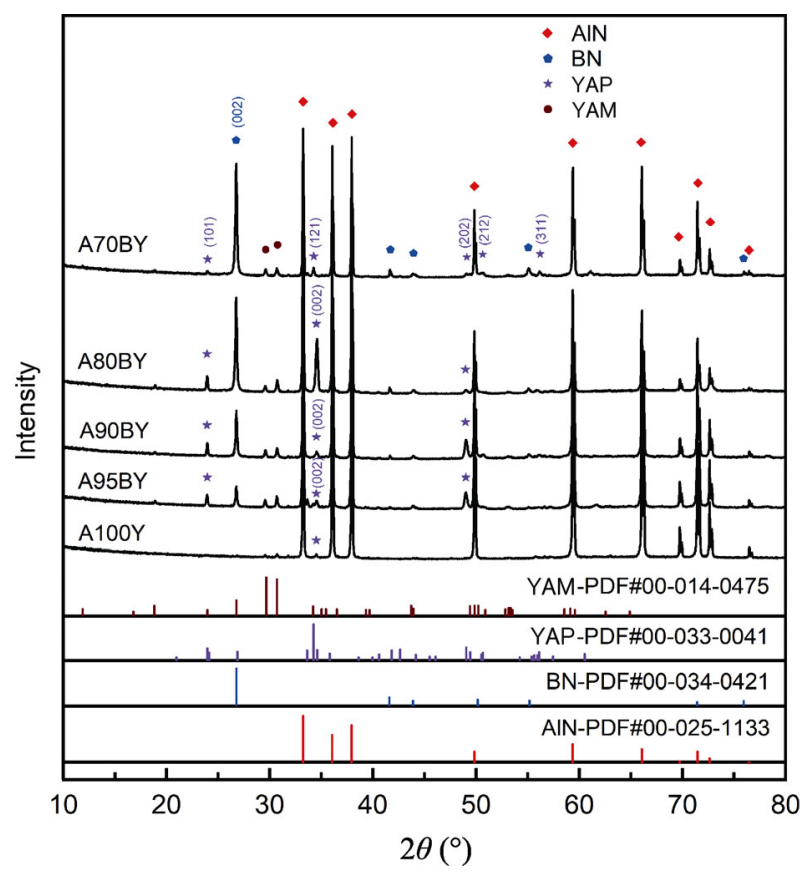

Fig. 1 XRD patterns of as-prepared AIN-h-BN composites. 


\section{2 Densification and microstructure}

Relative density of hot-pressed composites is presented in Table 2. With the increasing h-BN content in composites, the relative density of the composites increased with a relatively slower decrease after the increase. This can be attributed to the stomatal discharging and boron nitride grain growth in ceramics sintering process. While hot pressing $\mathrm{AlN}$ and $\mathrm{Y}_{2} \mathrm{O}_{3}$ powders without $\mathrm{BN}$ at $1900{ }^{\circ} \mathrm{C}$, since the low eutectic temperature for $\mathrm{Al}_{2} \mathrm{O}_{3}-\mathrm{Y}_{2} \mathrm{O}_{3}$ systems is around $1760{ }^{\circ} \mathrm{C}$, there was liquid phase in the sintering process under high temperature condition $[27,28]$. The high sintering temperature not only decreased the viscosity of $\mathrm{Y}-\mathrm{Al}-\mathrm{O}$ liquid phase to promote the liquid distribution, but also made the grain edges easily dissolve into the liquid phase [8]. In this case, AlN grains tended to overgrow, causing the pores between grains failure to evacuate in time, which had a negative impact on achieving full dense. As for the sample of A95BY, the degree of densification had a little growth when the BN content was increased to $5 \mathrm{wt} \%$, comparing with the sample of A100Y. This can be explained that existing of BN partly inhibited the diffusion of liquid phase by pinning each other between the different phases, which was beneficial to reduce the pores in the sintering process. However, the relative density decreased slightly with increasing BN content in the samples of A90BY, A80BY, and A70BY, because of the poor sinterability as well as the cleavable nature and the agglomeration of the $\mathrm{BN}$ platelets, which introduced some flaws into the matrix.

The back-scattered electron mode (BSE) images of the fracture AlN-h-BN composites are shown in Fig. 2. In all samples, it was found that the bright $\mathrm{Y}-\mathrm{A}-\mathrm{O}$ phase and light grey AIN grains are homogeneously distributed, besides the $\mathrm{Y}-\mathrm{A}-\mathrm{O}$ phase well distributed in intergranular and triangle grain boundaries. Although there is no significant color contrast between $\mathrm{BN}$ and

Table 2 Relative density, Vickers hardness, and thermal conductivity of composites with different content of $h-B N$

\begin{tabular}{ccccc}
\hline Sample & $\begin{array}{c}\text { Mass fraction } \\
\text { of h-BN (wt\%) }\end{array}$ & $\begin{array}{c}\text { Relative } \\
\text { density (\%) }\end{array}$ & $\begin{array}{c}\text { Vickers } \\
\text { hardness }(\mathrm{GPa})\end{array}$ & $\begin{array}{c}\text { Thermal } \\
\text { conductivity } \\
\left(\mathrm{W} \cdot \mathrm{m}^{-1} \cdot \mathrm{K}^{-1}\right)\end{array}$ \\
\hline A100Y & 0 & 98.64 & $9.83 \pm 0.22$ & $168.4 \pm 0.7$ \\
A95BY & 5 & 99.08 & $7.69 \pm 0.17$ & $130.2 \pm 0.6$ \\
A90BY & 10 & 99.06 & $7.29 \pm 0.13$ & $121.2 \pm 0.3$ \\
A80BY & 20 & 98.37 & $5.05 \pm 0.12$ & $98.3 \pm 0.4$ \\
A70BY & 30 & 97.96 & $3.52 \pm 0.07$ & $85.6 \pm 0.4$ \\
\hline
\end{tabular}

AlN grains (Figs. 2(b)-2(e)), the dispersion of BN grains around hexagonal AIN grains is observed according to its flake-like morphology, being increasingly obvious with the increase of the $\mathrm{BN}$ content, which is consistent with analysis results of density above. He et al. [21] prepared AlN-BN composites by sparking plasma sintering method with varying contents of hexagonal boron nitride. They reported that the layered boron nitride grains in composites also have the same distribution structure as this study through the microstructures of fracture surface. The average grain sizes of AlN in the samples of A100Y and A95BY5 are approximately 3.06 and $2.83 \mu \mathrm{m}$, respectively, as shown in Figs. 2(a) and 2(b), and the grain size is inhomogeneous that some grains perform evident overgrowth. Both transgranular and intergranular fractured grains are existed. The fracture morphology is relatively neat and distinct. With increasing the $\mathrm{BN}$ content, the AlN grain became smaller and smaller as shown in Figs. 2(c)-2(e). This indicates that the flake h-BN validly restrained the grain growth of AlN and avoided abnormal grains, showing that second phase was able to induce a proper pinning effect on refining grain. The pinning effect is similar to that observed in spark plasma sintering (SPS) AlN-BN composites [21]. Additionally, intergranular fracture turned to hold dominant position as shown in Figs. 2(c)-2(e).

Figure 3 shows TEM and HRTEM images of A80BY. It shows that $\mathrm{Y}-\mathrm{Al}-\mathrm{O}$ phase is existed between AlN and h-BN grains according to energy dispersive spectroscopy (EDS) analysis in Fig. 3(a). They are in close contact with neighborhood grains confirming to the high density mentioned previously. To understand the interface between different grains, the HRTEM image of triple grain boundary junction is shown in Fig. 3(b). It is clearly shown that the atomic transition region with thickness of about $5 \mathrm{~nm}$ exists between the different grains. The interlayer spacing in the picture region of lower right that has the distinguishable lattice fringes is 0.268 and $0.266 \mathrm{~nm}$, corresponding to the plane spacing of (100) of AlN and (200) of YAP, respectively.

\section{3 Mechanical properties}

Figure 4 shows the flexural strength and fracture toughness of sintered $\mathrm{AlN}-\mathrm{BN}$ composites with different content of h-BN. Both the flexural strength and fracture toughness present a trend of increasing first and then decreasing with increasing the $\mathrm{BN}$ content. When the 

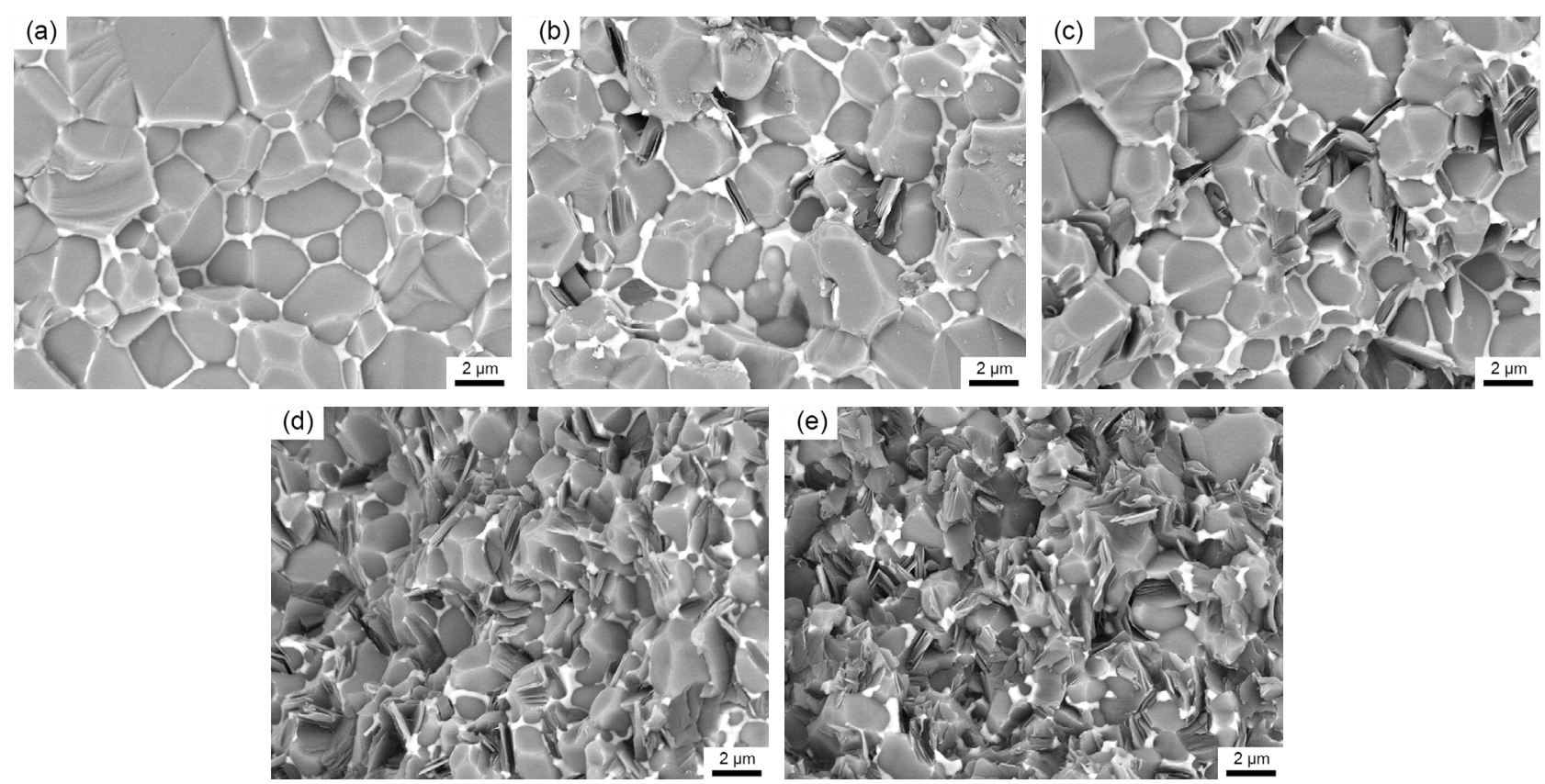

Fig. 2 BSE images of the fracture surface of sintered composites: (a) A100Y, (b) A95BY, (c) A90BY, (d) A80BY, and (e) A70BY.
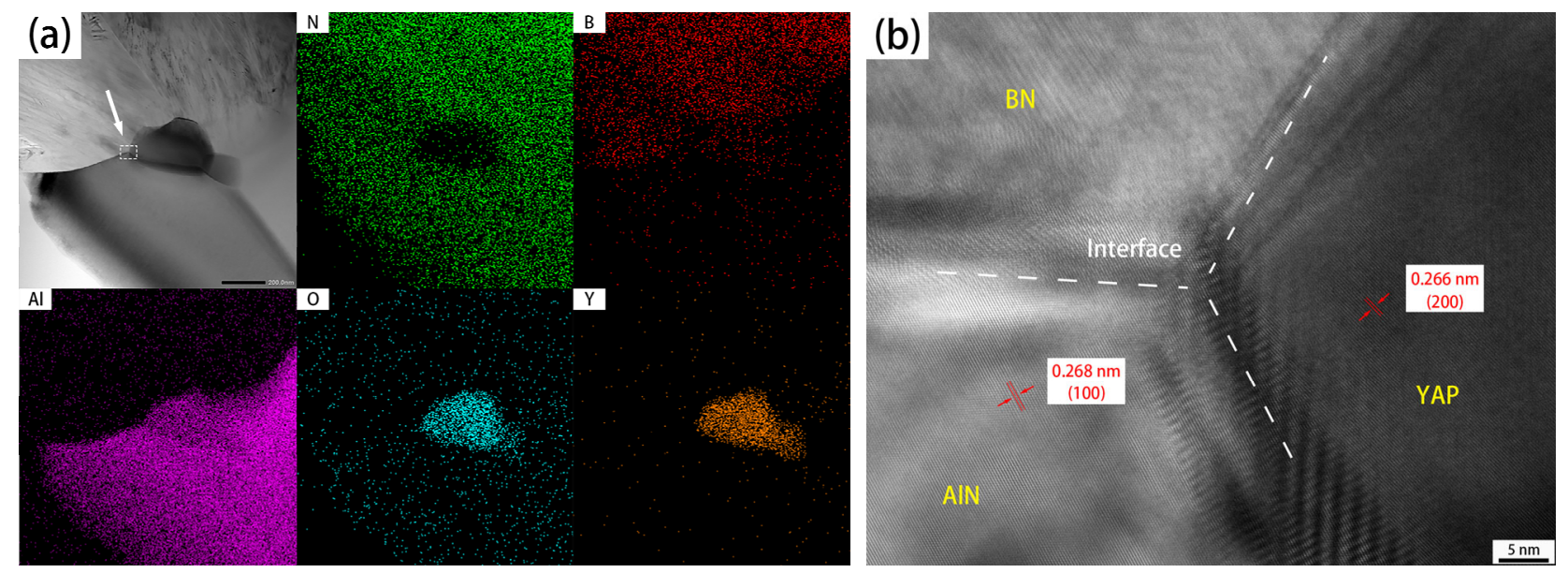

Fig. 3 (a) TEM image of A80BY with EDS analysis and (b) HRTEM image of triple junction marked in (a).

content of h-BN was $20 \mathrm{wt} \%$, the strength and toughness of the obtained AlN-BN reach its maximum of $475 \mathrm{MPa}$ and $4.86 \mathrm{MPa} \cdot \mathrm{m}^{1 / 2}$, respectively. When the content of h-BN is changed from 5 to $10 \mathrm{wt} \%$, the flexural strength and fracture toughness increase from $431 \mathrm{MPa}$ and $4.17 \mathrm{MPa} \cdot \mathrm{m}^{1 / 2}$ to $453 \mathrm{MPa}$ and $4.46 \mathrm{MPa} \cdot \mathrm{m}^{1 / 2}$, respectively, which is remarkably improved compared to AlN ceramic $\left(356 \mathrm{MPa}\right.$ and $3.11 \mathrm{MPa} \cdot \mathrm{m}^{1 / 2}$ ). On the other hand, the addition of sintering additive of $\mathrm{Y}_{2} \mathrm{O}_{3}$ formed the liquid phase environment on the surface of AlN grains in the high temperature stage. The liquid phases attempted to occupy the lowest free energy state because of the surface tension, filling the pores, and pulling the particles together. The YAP and YAM phases primarily dispersed at the isolated grain junction (as shown in Fig. 2) during final stage sintering, which enhanced the bonding strength between AIN grains. Comparing to sintering additive-free AlN-BN composite ceramics [22], the addition of $\mathrm{Y}_{2} \mathrm{O}_{3}$ played the crucial role in improving the strength of composites. On the other hand, the homogeneous dispersion of $\mathrm{h}-\mathrm{BN}$ and microcrack toughening also played a major part. Hexagonal boron nitride has a layered structure, and the layers are held together by van der Waals forces between each other. The good interfacial contact between the grains of each phase is beneficial to improve the mechanical properties of composites [29-31]. The lamellar structure is easily deformed and filled during the sintering process, which 
makes the two phases more closely bonded, and the addition of sintering additives reduces the formation of defects. Microcracks were inclined to propagate along the week joint surface between layers of h-BN and grain boundary of AlN, inducing microcrack deflection, branching, and bridging, which is contributed to absorption and consumption of breaking energy to improve the toughness. However, when h-BN mass fraction is $30 \%$, the flexural strength and facture toughness drop to $392 \mathrm{MPa}$ and $4.36 \mathrm{MPa} \cdot \mathrm{m}^{1 / 2}$, respectively. The attainment of such a change was attributed to the percolating network formed with the AlN matrix grains, reducing the contact area between grains. Furthermore, the agglomeration of $\mathrm{h}-\mathrm{BN}$ as a relatively weak phase also deteriorated the mechanical properties of the composites.

The influence of the h-BN content on the Vickers hardness is summarized in Table 2. The Vickers hardness of AlN-BN composites in the study is $3.52-9.83 \mathrm{GPa}$. The hardness of the composites decreased gradually with increasing h-BN content compared to monolithic AlN. This is expected from the rule of mixtures because h-BN is a soft material that its hardness ranges from 0.20 to $0.25 \mathrm{GPa}$ in different orientations [32]. The Vickers hardness of carbide tool commonly used in commercial application is between 13.6 and $17 \mathrm{GPa}$, which ensures that the composite ceramic in this paper could be processed by carbide tools. In particular, the higher the boron nitride content, the easier the processing.

\section{4 Thermal conductivity}

In this study, the thermal conductivity of the samples with different h-BN content is summed in Table 2. For

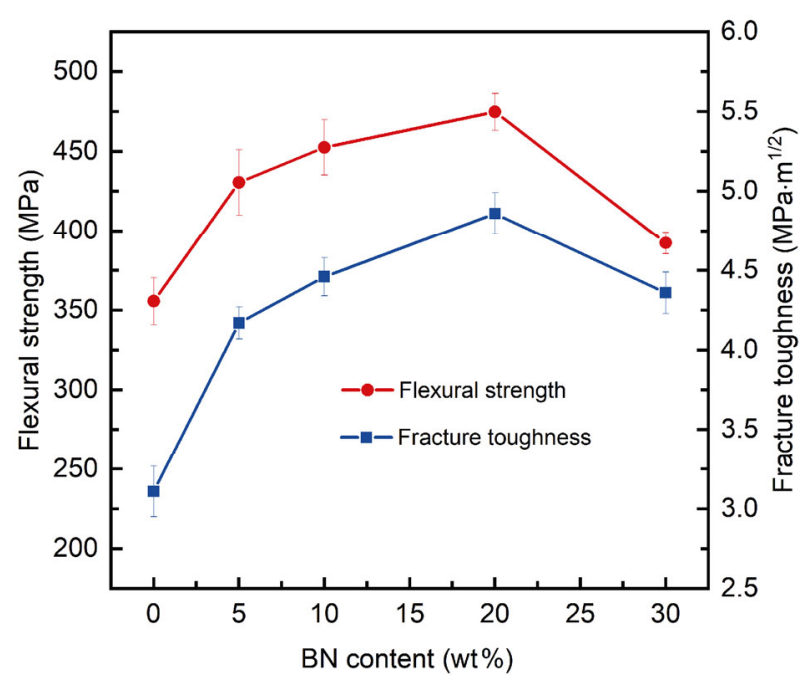

Fig. 4 Flexural strength and fracture toughness of composites with different BN content. the single-phase AlN ceramic, the impurity of oxide has an adverse influence on the thermal conductivity, since the oxidation layer on the surfaces of AIN particles blocks the direct connection between the aluminum nitride lattices and diffuses into the lattice to produce aluminum vacancies during the sintering [25,33]. When introducing the sintering aid of yttria, it reacted with oxygen impurity at high temperature and thereby reduced the free oxygen content [34]. Besides, the yttrium-aluminate phases are mainly dispersed at the separated AlN grain junctions rather than along the grain boundaries completely, avoiding completely scattering of phonons [35]. The thermal conductivity of composites monotonically decreases with h-BN content increasing. The minimum value is $85.6 \mathrm{~W} \cdot \mathrm{m}^{-1} \cdot \mathrm{K}^{-1}$ when the $\mathrm{BN}$ content is up to $30 \mathrm{wt} \%$, which still shows a relatively good thermal conductivity. It can be explained that AlN and h-BN mainly conduct heat transfer through phonons, while grain boundaries and second phases affect the continuity of lattice vibrations. In addition, the thermal conductivity in the (0001) lattice face orientation is far greater than the direction between layers because of the anisotropic crystal structure of h-BN. Kusunose and Sekino [36] prepared the highly oriented h-BN by hot pressed sintering and studied the thermal conductivity of different orientations. The results show that the thermal conductivity perpendicular to the hot-pressing direction was greater than $120 \mathrm{~W} \cdot \mathrm{m}^{-1} \cdot \mathrm{K}^{-1}$; nevertheless, the thermal conductivity parallel to the hot-pressing direction was as low as $10 \mathrm{~W} \cdot \mathrm{m}^{-1} \cdot \mathrm{K}^{-1}$. As the boron nitride content increased, more $\mathrm{BN}$ randomly dispersed around the AlN grain inhibiting the excessive growth of it, which could bring about the enhancement of phonon scattering and thereby lowering the thermal conductivity. In previous studies, the thermal conductivity value of AlN ceramic prepared by plasma sintering was $148 \mathrm{~W} \cdot \mathrm{m}^{-1} \cdot \mathrm{K}^{-1}$ with the optimal amount of doped $-\mathrm{Y}_{2} \mathrm{O}_{3}$ aid [37], and the thermal conductivity of AlN-BN composites ranged from 109.8 to $58 \mathrm{~W} \cdot \mathrm{m}^{-1} \cdot \mathrm{K}^{-1}$ using $\mathrm{Sm}_{2} \mathrm{O}_{3}-\mathrm{CaF}_{2}$ as sintering additives with h-BN content increasing [21], which is lower than that of this paper.

\section{5 Dielectric property}

The dielectric properties of $\mathrm{AlN}-\mathrm{BN}$ composites with different h-BN content at $22-26 \mathrm{GHz}$ are shown in Fig. 5. The real part of the dielectric constant decreases with the increase of frequency, and there is a small fluctuation in samples A90BY and A95BY. In the test frequency, the average of the relative permittivity of 
$\mathrm{A} 100 \mathrm{Y}, \mathrm{A} 95 \mathrm{BY} 5, \mathrm{~A} 90 \mathrm{BY} 5, \mathrm{~A} 80 \mathrm{BY} 5$, and A70BY5 is 8.3, 7.8, 7.6, 7.0, and 6.8, respectively. He et al. [38] and Kume et al. [39] prepared AlN ceramics using $\mathrm{Y}_{2} \mathrm{O}_{3}-$ $\mathrm{CaF}_{2}$ as sintering additives by SPS method and studied the dielectric properties at $18-40 \mathrm{GHz}$. The results show that the relative dielectric constant changed from 8 to 8.5 , which was nearly the same as the sample of A100Y in this study. Since the dielectric constant of h-BN is around 4 and lower than that of AlN [40,41], the relative permittivity of the composites decreases monotonously with the increase of boron nitride content, as shown in Fig. 5(a). In terms of dielectric loss tangent $(\tan \delta)$, the mean value of $\tan \delta$ of A100Y, A95BY5, A90BY5, $\mathrm{A} 80 \mathrm{BY} 5$, and A70BY5 is $4.4 \times 10^{-3}, 2.4 \times 10^{-3}, 4.3 \times$ $10^{-3}, 4.2 \times 10^{-3}$, and $6.4 \times 10^{-3}$, respectively, as shown in Fig. 5(b). On one hand, oxygen impurities had a clear effect on the dielectric loss of AlN ceramics at high frequency [42]. Since the sintering additives reacted with alumina at high temperature, the oxygen impurities in the crystal lattice were easily diffused to the gain surface for reaction, which reduced the oxygen vacancy
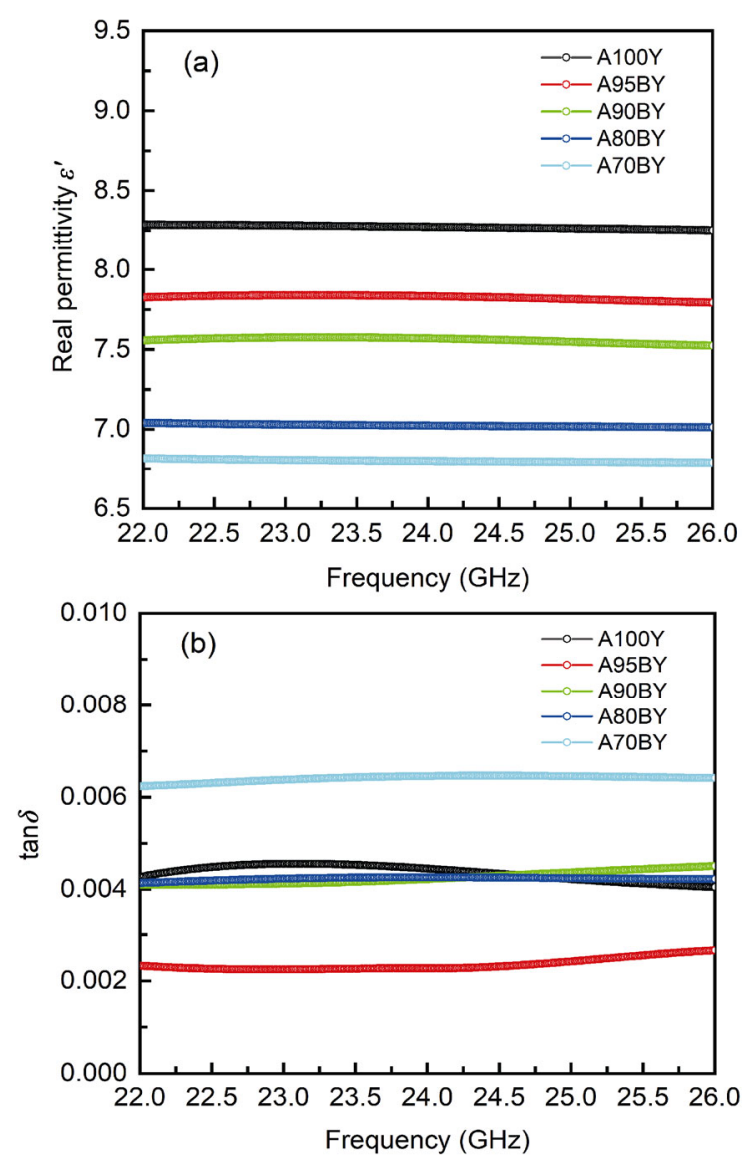

Fig. 5 (a) Relative permittivity ( $\left.\varepsilon^{\prime}\right)$ and (b) dielectric loss $(\tan \delta)$ of AlN-BN composites with different h-BN content at $22-26 \mathrm{GHz}$. in the composites. This is one reason that all samples have low dielectric loss. On the other hand, the crystal imperfection leads to extrinsic loss deterioration, such as microcracks, pores, grain boundaries, impurities, and defects $[39,43,44]$. When the content of boron nitride in composites increases, defects and pores are more likely to be introduced. This is the important reason for that the sample of $\mathrm{A} 70 \mathrm{BY}$ has higher $\tan \delta$ value and $\mathrm{A} 95 \mathrm{BY}$ has lower $\tan \delta$ value compared to other samples, relating to relative density and h-BN content.

\section{Conclusions}

Fully dense AlN-h-BN composite ceramics were fabricated by hot pressing method with $50 \mathrm{MPa}$ uniaxial pressure at $1900{ }^{\circ} \mathrm{C}$. The sintering aid of $\mathrm{Y}_{2} \mathrm{O}_{3}$ formed the liquid phase by reaction with the oxide on the surface of AlN particles in the high temperature sintering process, enhancing the bonding of grains. With the increase of boron nitride content, the agglomeration of its stratified structure introduced some flaws, which slightly reduced density. Vickers hardness and thermal conductivity decreased with increasing h-BN content. Lower hardness and layered dissociable structure enhanced the machinability of the composites. Flexural strength and fracture toughness increased firstly and then decreased. When the content of h-BN was $20 \mathrm{wt} \%$, the strength and toughness of the obtained AlN-BN reached its maximum of $475 \mathrm{MPa}$ and $4.86 \mathrm{MPa} \cdot \mathrm{m}^{1 / 2}$, respectively, and the thermal conductivity was $98.3 \mathrm{~W} \cdot \mathrm{m}^{-1} \cdot \mathrm{K}^{-1}$. The relative dielectric constant and dielectric loss tangent of the samples ranged from 6.8 to 8.3 and from $2.4 \times 10^{-3}$ to $6.4 \times 10^{-3}$, respectively, in $22-26 \mathrm{GHz}$, relating to the dielectric properties and microcosmic defects between the two phases.

\section{Acknowledgements}

This work was supported by the Basic Science Center Project of NSFC (Grant No. 51788104), as well as the National Natural Science Foundation of China (Grant Nos. 51532004 and 11704216).

\section{References}

[1] Michálek M, Michálková M, Blugan G, et al. Strength of pure alumina ceramics above $1 \mathrm{GPa}$. Ceram Int 2018, 44: 3255-3260.

[2] Abyzov AM. Aluminum oxide and alumina ceramics 
(review). Part 1. Properties of $\mathrm{Al}_{2} \mathrm{O}_{3}$ and commercial production of dispersed $\mathrm{Al}_{2} \mathrm{O}_{3}$. Refract Ind Ceram 2019, 60: $24-32$.

[3] Akishin GP, Turnaev SK, Vaispapir VY, et al. Thermal conductivity of beryllium oxide ceramic. Refract Ind Ceram 2009, 50: 465-468.

[4] Rutkowski PJ, Kata D. Thermal properties of AIN polycrystals obtained by pulse plasma sintering method. $J$ Adv Ceram 2013, 2: 180-184.

[5] Mashhadi HA, Manikandan P, Suetsugu R, et al. Synthesis of AlN-TiN nanostructured composite powder by reactive ball milling and subsequent thermal treatment. $J$ Alloys Compd 2010, 506: 653-660.

[6] Chen W, Miyamoto Y, Tojo T, et al. Densification and properties of AlN ceramic bonded carbon. J Eur Ceram Soc 2012, 32: 245-250.

[7] Lee HM, Kim DK. High-strength AlN ceramics by lowtemperature sintering with $\mathrm{CaZrO}_{3}-\mathrm{Y}_{2} \mathrm{O}_{3}$ co-additives. $J$ Eur Ceram Soc 2014, 34: 3627-3633.

[8] Qiao L, Chen SW, Jiang LQ, et al. Sintering behavior of aluminum nitride powder prepared by self-propagating high-temperature synthesis method. Rare Met 2018, 37: 1091-1095.

[9] Amy C, Budenstein D, Bagepalli M, et al. Pumping liquid metal at high temperatures up to 1,673 kelvin. Nature 2017, 550: 199-203.

[10] Terao R, Tatami J, Meguro T, et al. Fracture behavior of AlN ceramics with rare earth oxides. $J$ Eur Ceram Soc 2002, 22: 1051-1059.

[11] Zhang GJ, Yang JF, Ohji T. In situ $\mathrm{Si}_{3} \mathrm{~N}_{4}-\mathrm{SiC}-\mathrm{BN}$ composites: Preparation, microstructures and properties. Mater Sci Eng: A 2002, 328: 201-205.

[12] Yang ZH, Jia DC, Zhou Y, et al. Oxidation resistance of hot-pressed SiC-BN composites. Ceram Int 2008, 34: 317-321.

[13] Zhai HZ, Cai HN, Yang XZ, et al. Preparation and properties of $\mathrm{BN}-\mathrm{SiO}_{2}$ composite ceramics. Key Eng Mater 2007, 336-338: 1426-1428.

[14] Li Y, Qiao G, Jin Z. Machinable $\mathrm{Al}_{2} \mathrm{O}_{3} / \mathrm{BN}$ composite ceramics with strong mechanical properties. Mater Res Bull 2002, 37: 1401-1409.

[15] Wang R, Pan W, Chen J, et al. Fabrication and characterization of machinable $\mathrm{Si}_{3} \mathrm{~N}_{4} / \mathrm{h}-\mathrm{BN}$ functionally graded materials. Mater Res Bull 2002, 37: 1269-1277.

[16] Zhong B, Zhao GL, Huang XX, et al. Microstructure and mechanical properties of ZTA/BN machinable ceramics fabricated by reactive hot pressing. J Eur Ceram Soc 2015, 35: 641-649.

[17] Cho WS, Piao ZH, Lee KJ, et al. Microstructure and mechanical properties of AlN-hBN based machinable ceramics prepared by pressureless sintering. J Eur Ceram Soc 2007, 27: 1425-1430.

[18] Cho WS, Cho MW, Lee JH, et al. Effects of h-BN additive on the microstructure and mechanical properties of AlNbased machinable ceramics. Mater Sci Eng: A 2006, 418:
$61-67$.

[19] Jin HY, Wang W, Gao JQ, et al. Study of machinable AlN/BN ceramic composites. Mater Lett 2006, 60: 190193.

[20] Makarenko GN, Krushinskaya LA, Fedorus VB, et al. Production and properties of AlN-BN composite. Powder Metall Met Ceram 2011, 49: 670-674.

[21] He X, Gong Q, Guo Y, et al. Microstructure and properties of AlN-BN composites prepared by sparking plasma sintering method. J Alloys Compd 2016, 675: 168-173.

[22] Jin C, Wang T, Pan L, et al. Preparation and properties of sintering additive-free AlN-BN composite ceramics by hot-pressing sintering. J Mater Sci: Mater Electron 2016, 27: 2014-2021.

[23] Boughriet A, Legrand C, Chapoton A. Noniterative stable transmission/reflection method for low-loss material complex permittivity determination. IEEE Trans Microw Theory Tech 1997, 45: 52-57.

[24] Lee SH, Tanaka H, Aoyagi T. Densification of AlN using boron and carbon additives. J Eur Ceram Soc 2009, 29: 2021-2027.

[25] He X, Ye F, Zhou Z, et al. Thermal conductivity of Spark Plasma Sintered AIN ceramics with multiple components sintering additive. J Alloys Compd 2010, 496: 413-417.

[26] Huang D, Tian Z, Cui W, et al. Effects of $\mathrm{Y}_{2} \mathrm{O}_{3}$ and yttrium aluminates as sintering additives on the thermal conductivity of AlN ceramic substrates. Ceram Int 2018, 44: 20556-20559.

[27] Molisani A, Yoshimura H, Goldenstein H. Sintering mechanisms in aluminum nitride with $\mathrm{Y}$ or Ca-containing additive. J Mater Sci: Mater Electron 2009, 20: 1-8.

[28] Molisani AL, Goldenstein H, Yoshimura HN. The role of $\mathrm{CaO}$ additive on sintering of aluminum nitride ceramics. Ceram Int 2017, 43: 16972-16979.

[29] Han X, Huang Y, Gao Q, et al. Effects of nanotube content on thermal and mechanical properties of $\mathrm{NT} @ \mathrm{Cu} /$ Ag@GF/Al composites. J Alloys Compd 2018, 766: 594600.

[30] Han X, Huang, Y, Gao Q, et al. High thermal conductivity and mechanical properties of nanotube@ $\mathrm{Cu} / \mathrm{Ag} @$, graphite/aluminum composites. Ind Eng Chem Res 2018, 57, 10365-10371.

[31] Han X, Huang Y, Wang J, et al. Fabrication of graphite films/copper composites by vacuum hot pressing for high-efficiency thermal management property. Compos Commun 2021, 24: 100665.

[32] Ertug B, Boyraz T, Addemir O. An investigation of the mechanical properties and fracture characteristic of hot-pressed boron nitride ceramics. Mater Sci Forum 2007, 554: 201-205.

[33] Zhou H, Qiao L, Fu R. Effect of the fluoride additives on the oxidation of AlN. Mater Res Bull 2002, 37: 24272435.

[34] Baik Y, Drew RAL. Aluminum nitride: Processing and applications. Key Eng Mater 1996, 122-124: 553-570. 
[35] Yu YD, Hundere AM, Høier R, et al. Microstructural characterization and microstructural effects on the thermal conductivity of $\mathrm{AlN}\left(\mathrm{Y}_{2} \mathrm{O}_{3}\right)$ ceramics. J Eur Ceram Soc 2002, 22: 247-252.

[36] Kusunose T, Sekino T. Thermal conductivity of hot-pressed hexagonal boron nitride. Scripta Mater 2016, 124: 138-141.

[37] Li YL, Zhang J, Zhang JX. Fabrication and thermal conductivity of AlN/BN ceramics by spark plasma sintering. Ceram Int 2009, 35: 2219-2224.

[38] He X, Shi L, Guo Y, et al. Study on microstructure and dielectric properties of aluminum nitride ceramics. Mater Charact 2015, 106: 404-410.

[39] Kume S, Yasuoka M, Lee SK, et al. Dielectric and thermal properties of AlN ceramics. J Eur Ceram Soc 2007, 27: 2967-2971.

[40] Petrone N, Chari T, Meric I, et al. Flexible graphene field-effect transistors encapsulated in hexagonal boron nitride. ACS Nano 2015, 9: 8953-8959.

[41] Couderc H, Fréchette M, Savoie S, et al. Dielectric and thermal properties of boron nitride and Silica epoxy composites. In: Proceedings of the 2012 IEEE International Symposium on Electrical Insulation, 2012: 64-68.

[42] Kume S, Yasuoka M, Omura N, et al. Annealing effect on dielectric property of AlN ceramics. J Eur Ceram Soc
2006, 26: 1831-1834.

[43] Fesenko I P, Kuzenkova MA. Low dielectric loss ceramics of AlN fine and nanopowders. Powder Metall Met Ceram 2002, 41: 567-569.

[44] Kume S, Yasuoka M, Omura N, et al. Effects of $\mathrm{MgO}$ addition on the density and dielectric loss of AIN ceramics sintered in presence of $\mathrm{Y}_{2} \mathrm{O}_{3}$. J Eur Ceram Soc 2005, 25: 2791-2794.

Open Access This article is licensed under a Creative Commons Attribution 4.0 International License, which permits use, sharing, adaptation, distribution and reproduction in any medium or format, as long as you give appropriate credit to the original author(s) and the source, provide a link to the Creative Commons licence, and indicate if changes were made.

The images or other third party material in this article are includ ed in the article's Creative Commons licence, unless indicated otherwise in a credit line to the material. If material is not included in the article's Creative Commons licence and your intended use is not permitted by statutory regulation or exceeds the permitted use, you will need to obtain permission directly from the copyright holder.

To view a copy of this licence, visit http://creativecommons. org/licenses/by/4.0/. 